\title{
Evaluation of Physiological Cost and Subjective Assessment of Power Paddy Weeder for Wet Land Paddy
}

\author{
Bini Sam \\ Associate Professor (Farm Machinery), Kerala Agricultural University, Kerala, India
}

\begin{abstract}
Mechanical weeders are performing activities such as weeding and hoeing simultaneously and thus reduces the time, cost and drudgery involved in manual weeding.The physiological response of the subject was assessed while operating a power paddy weeder for weeding paddy in wet land cultivation. The cardiac cost involved in the operation of power paddy weeder was found out and the mean working heart rate value of the subject was 108 beats min $^{-1}$. The energy expended during operation of a power paddy weeder was 19. $50 \mathrm{~kJ} \mathrm{~min}^{-1}$. The oxygen uptake in terms of $\mathrm{VO}_{2}$ max was $46 \%$ which was above the acceptable limit of $35 \%$ of $\mathrm{VO} \mathrm{O}_{2}$ max. The weeding efficiency was found to be $85 \%$. Area covered by the power paddy weeder was 25 cent/hour ((row to row spacing is $23.8 \mathrm{~cm}$ while using self propelled rice transplanter) and area covered by the power paddy weeder was 30 cent/hour while planting $30 \mathrm{~cm}$ row spacing. The machine requires 0.5 litre petrol to cove $1 \mathrm{hr}$. Mean overall discomfort rating on a 10 point visual analogue discomfort scale ( 0- no discomfort, 10- extreme discomfort) was 3.0 and scaled as "light discomfort". More tillers have been produced after using this equipment and soil aeration and root growth was improved. It is comfortable to operate this machine. If only one worker is engaged for the weeding operation with this equipment, 7 min rest could be provided after operating the equipment continuously for the 30 min period.
\end{abstract}

Keywords: power paddy weeder, heart rate, oxygen uptake in terms of $\mathrm{VO}_{2}$ max, weeding efficiency, discomfort.

\section{Introduction}

The most common methods of weed control are mechanical, chemical, biological and cultural methods. Out of these four methods, mechanical weeding either by hand tools or weeders are most effective in both dry land and wet land cultivation (Nag and Datt, 1979; Gite and Yadav, 1990). Weeding with the use of manual tools requires high labour force. Mechanical weeders are used to complete the weeding operation in due time at less cost. Environmental pollution caused by chemical is also reduced by the use of mechanical weeder.

The performance of man implement system may be poor, if ergonomics aspect are not given due attention. Proper attention to ergonomics aspects in design and operation will help increasing man implement efficiency and also in safe guarding the workers health. Farm implements and machinery hitherto have not been ergonomically designed and developed. Hence there is an urgent need to study the ergonomic aspects in detail to qualify the drudgery involved in the agricultural operations. This would greatly help the researchers to appropriately design simple and labour effective gadgets considering ergonomic requirements. Thus, investigations on ergonomical evaluation of power paddy weeder can provide a rational basis for recommendation of methods and improvement in equipment design for more output and safety.

\section{Materials and Methods}

\subsection{Subjects}

Three healthy male operators based on age and medical fitness were selected for the study. The strength or power is expected to be maximum in the age group of 25 to 35 years
(Grandjean, 1982; Gite and Singh, 1997). Hence three subjects were chosen from the age group of 25 to 35 years. The physiological characteristics of selected subjects are given in Table 1.

Table 1: Physiological characteristics of participants

\begin{tabular}{|c|c|c|c|c|}
\hline S. & Variable & \multicolumn{3}{|c|}{ Subjects } \\
\cline { 3 - 5 } No & & 1 & II & III \\
\hline 1 & Age, years & 29 & 26 & 33 \\
\hline 2 & Body weight, kg & 65 & 52 & 70 \\
\hline 3 & Height, $\mathrm{m}$ & 1.65 & 1.63 & 1.83 \\
\hline 4 & Resting heart rate, beats $\mathrm{min}^{-1}$ & 60.00 & 69.00 & 69.00 \\
\hline 5 & ECG & Normal & Normal & Normal \\
\hline 6 & Blood pressure, $\mathrm{mm}$ of $\mathrm{Hg}$ & $120 / 80$ & $120 / 80$ & $120 / 80$ \\
\hline
\end{tabular}

\subsection{Establishing relationship between Oxygen uptake} and Heart Rate

On a separate day and before performing activities, the relationship between heart rate and oxygen uptake for each subject was determined. This relationship is used to indirectly evaluate physiological workload. Both heart rate and oxygen uptake have to be measured simultaneously in the laboratory at a number of different submaximal workloads. This process is known as calibrating the heart rate- $\mathrm{VO}_{2}$ relationship for a subject. Since the relationship between the two variables is linear during a typical submaximal workload, a subject's heart rate measured in the field can be converted into an estimate of oxygen uptake by referring to the laboratory data. The oxygen consumption was measured using Benedict-Roth spirometer and the heart beat rate was recorded using heart rate monitor (Polar make).

\subsection{Field layout experiments}

The experiment was conducted in farmers feld in Chadayamangalam Block of Kollam District, Kerala, India. 


\section{International Journal of Science and Research (IJSR) \\ ISSN (Online): 2319-7064}

Index Copernicus Value (2013): 6.14 | Impact Factor (2014): 5.611

Power paddy weeder is a manually operated implement powered by $1.75 \mathrm{Hp}$ petrol engine and designed to work in two rows of 20 to $30 \mathrm{~cm}$ spacing in wet lands. It works by the rotary motion of blades and the weeds were uprooted and buried in the field itself. A float provided in the front portion prevents the unit from sinking into the puddled soil. It disturbs the topsoil and increases the aeration also. The specification of the equipment is shown in Table 2.

Table 2: Specification of the power paddy weeder

\begin{tabular}{|c|c|c|}
\hline S. No: & Description & Specification \\
\hline 1 & Engine type & Petrol engine \\
\hline 2 & Power & $1.75 \mathrm{Hp}$ \\
\hline 3 & Fuel & $\begin{array}{c}\text { Petrol ( 11t petrol+ 30 } \\
\text { ml 2T oil) }\end{array}$ \\
\hline 4 & RPM & 6500 \\
\hline 5 & Rotavator speed & $300 \mathrm{rpm}$ \\
\hline 6 & Starter & Recoil Starter \\
\hline 7 & No. of weeding wheels/blades & 2 nos \\
\hline 8 & No. of teeth in each wheel & 4 \\
\hline 9 & Weeding width & 45 to $60 \mathrm{~cm}$ \\
\hline 10 & Weight & $17 \mathrm{~kg}$ \\
\hline 11 & Fuel tank Capacity & $1.1 \mathrm{lt}$ \\
\hline 12 & Gear box capacity & $150 \mathrm{ml}$ \\
\hline
\end{tabular}

The power paddy weeder was put in proper test condition before conducting the tests. All the three subjects were equally trained in the operation of the power paddy weeder. They were asked to report at the work site at 7.30 am and have a rest for 30 minutes before starting the trial. The subjects were given information about the experimental requirements so as to enlist their full cooperation.
The heart rate was measured and recorded using heart rate monitor for the entire work period. Each trial started with taking five minutes data for physiological responses of the subjects while resting on a stool under shade. They were then asked to operate the power paddy weeder (already started by another person) for duration of 15 minutes and same procedure was repeated to replicate the trials for all the selected subjects.

\subsection{Data Analysis}

The recorded heart rate values from the computerized heart rate monitor were transferred to the computer and the values of heart rate at resting level and from 6th to 15th minute of operation were taken for calculating the physiological responses of the subjects. The stabilized values of heart rate for each subject from $6^{\text {th }}$ to $15^{\text {th }}$ minute of operation were used to calculate the mean value for power paddy weeder. From the mean values of heart rate (HR) observed during the trials, the corresponding values of oxygen consumption rate $\left(\mathrm{VO}_{2}\right)$ of the subjects were predicted from the calibration curves of the subjects. The energy costs of the operations were computed by multiplying the value of oxygen consumption (mean of the values of three subjects) by the calorific value of oxygen as $20.88 \mathrm{~kJ}$ lit-1 (Nag et al., 1980). The energy cost of the subjects thus obtained was graded as per the tentative classification of strains in different types of jobs given in ICMR report as shown in Table 3 (Sen, 1969 and Sam, 2014).

Table 3: Tentative classification of strains (ICMR) in different types of jobs

\begin{tabular}{|c|c|c|c|}
\hline \multirow{2}{*}{ Grading } & \multicolumn{3}{|c|}{ Physiological response } \\
\cline { 2 - 4 } & Heart rate $\left(\right.$ beats $\mathrm{min}^{-1}$ ) & Oxygen uptake, lit min & Energy expenditure, kcal min $^{-1}$ \\
\hline Very light & $<75$ & $<0.35$ & $<1.75$ \\
\hline Light & $75-100$ & $0.35-0.70$ & $1.75-3.5$ \\
\hline Moderately heavy & $100-125$ & $0.70-1.05$ & $3.5-5.25$ \\
\hline Heavy & $125-150$ & $1.05-1.40$ & $5.25-7.00$ \\
\hline Very heavy & $150-175$ & $1.40-1.75$ & $7.00-8.75$ \\
\hline Extremely heavy & $>175$ & $>1.75$ & $>8.75$ \\
\hline
\end{tabular}

\subsection{Assessment of Postural Discomfort}

Assessment of postural discomfort included overall discomfort rating (ODR) and body part discomfort score (BPDS). The subjects were asked to report at the work site at $8.00 \mathrm{AM}$ and have a rest for 30 minutes before starting the trial. After 30 minutes of resting, the subject was asked to operate the power paddy weeder for duration of two hours. Sufficient rest period was given for each subject between the two trials on the same day with the same subject.

\subsubsection{Overall discomfort rating (ODR)}

For the assessment of ODR, a 10 - point psychophysical rating scale (0 - no discomfort, 10 - extreme discomfort) was used which is an adoption of Corlett and Bishop (1976) technique. A scale of $70 \mathrm{~cm}$ length was fabricated having 0 to 10 digits marked on it equidistantly (Fig.1). A movable pointer was provided on the scale to indicate the rating.

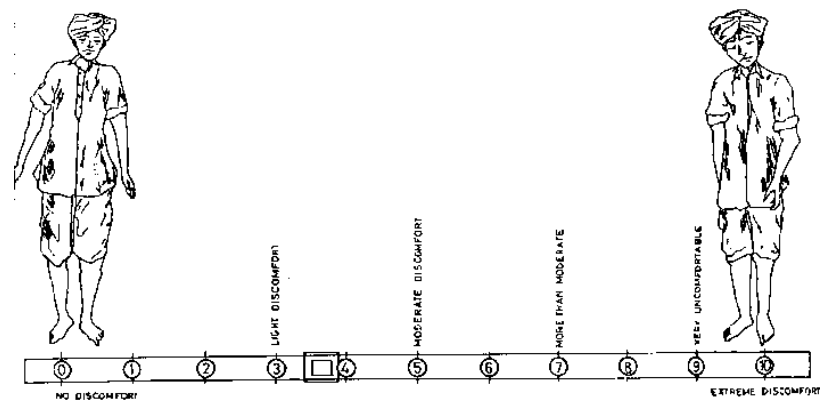

Figure 1: Visual analogue discomfort scale for assessment of overall body discomfort

At the ends of each trial subjects were asked to indicate their overall discomfort rating on the scale. The overall discomfort ratings given by each of the three subjects were added and averaged to get the mean rating. 


\section{International Journal of Science and Research (IJSR) \\ ISSN (Online): 2319-7064}

Index Copernicus Value (2013): 6.14 | Impact Factor (2014): 5.611

\subsubsection{Body part discomfort score (BPDS)}

To measure localized discomfort, Corlett and Bishop (1976) technique was used. In this technique the subject's body is divided into 27 regions as shown in Fig.2. A body mapping similar to that of Fig.2 was made to have a real and meaningful rating of the perceived exertion of the subject. The subject was asked to mention all body parts with discomfort, starting with the worst and the second worst and so on until all parts have been mentioned. The subject was asked to fix the pin on the body part in the order of one pin for maximum pain, two pins for next maximum pain and so on. The body part discomfort score of each subject was the rating multiplied by the number of body parts corresponding to each category. The total body part score for a subject was the sum of all individual scores of the body parts assigned by the subject. The body discomfort score of all the subjects was added and averaged to get a mean score.
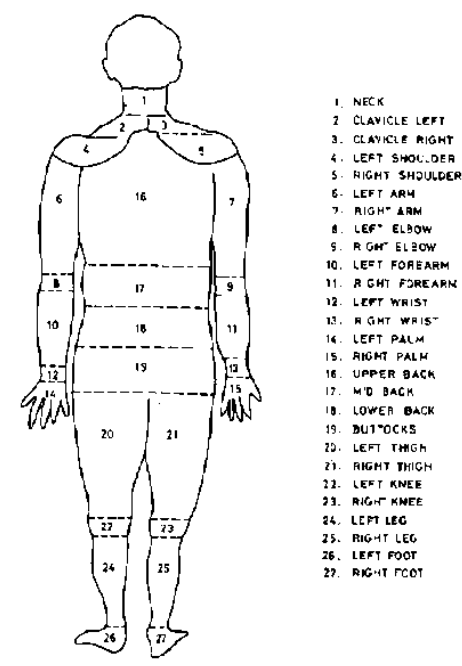

Figure 2: Regions for evaluating body part discomfort score

Weeding Efficiency was calculated by using the following formula (Anon 1985).

$\mathrm{e}=\left[\left(\mathrm{W}_{1}-\mathrm{W}_{2}\right) / \mathrm{W}_{1}\right] \times 100$

Where,

$\mathrm{e}=$ weeding efficiency, per cent

$\mathrm{W}_{1}=$ number of weeds $/ \mathrm{m}^{2}$ before weeding

$\mathrm{W}_{2}=$ number of weeds $/ \mathrm{m}^{2}$ after weeding

Higher the value (e) means the weeder is more efficient to remove the weeds.

\section{Results and Discussion}

\subsection{Calibration Process}

By using the data on heart rate and oxygen consumption rate, calibration chart was prepared with heart rate as the abscissa and the oxygen uptake as the ordinate for the selected three subjects.

It is observed that the relationship between the heart rate and oxygen consumption of the subjects was found to be linear for all the subjects. This linear relationship defers from one individual to another due to physiological differences of individuals (Kroemer et al., 2000). The relationship between the two parameters oxygen consumption $(\mathrm{Y})$ and heart rate (X) was expressed by the following linear equations.

For subject I, $\mathrm{Y}=0.0152 \mathrm{X}-0.8824\left(\mathrm{R}^{2}=0.9628\right)$--- (1)

For subject II, Y $=0.0199 \mathrm{X}-1.2505\left(\mathrm{R}^{2}=0.9849\right)---(2)$

For subject III, Y $=0.0156 \mathrm{X}-0.7415\left(\mathrm{R}^{2}=0.9575\right)$--- $(3)$

Where,

$\mathrm{Y}=$ Oxygen consumption, $1 \mathrm{~min}^{-1}$

$\mathrm{X}=$ Heart rate, beats $\min ^{-1}$

It is observed that $\mathrm{R}^{2}$ value (coefficient of determination) was very high for all the subjects which indicated that a good fit was arrived between oxygen consumption and heart rate.

\subsection{Energy cost of operation}

The average working heart rate of the operator was 108 beats $\min ^{-1}$ and the corresponding value of oxygen consumption rate predicted from the calibration chart was $0.9341 \mathrm{~min}^{-1}$. The corresponding energy expenditure was 19 . $50 \mathrm{~kJ} \mathrm{~min}^{-1}$. Based on the mean energy expenditure, the operation was graded as "Moderately Heavy" . In power paddy weeder, the subjects can do the weeding in a standing posture ( Fig.3) . But in hand weeding the subjects were bending over work surfaces for targets which are too low. It may be suggested that pain rather than capacity may often be the limiting factor in such task situations.

More tillers have been produced in the case of power paddy weeder compared to cono weeder. The weeding index was found to be $85 \%$. Area covered by the power paddy weeder was 25 cent/hour while for cono weeder it was 15 cent/ hour for mechanical transplanted paddy (row to row spacing is $23.8 \mathrm{~cm}$ while using self propelled rice transplanter). It is more comfortable to operate power paddy weeder. The paddy weeder improves soil aeration and root growth. The disadvantages are starting torque is less and row to row distance should be correct.

\subsection{Acceptable workload (AWL)}

To ascertain whether the operations selected for the trails were within the acceptable workload (AWL), the oxygen uptake in terms of $\mathrm{VO}_{2} \max (\%)$ was computed. Saha et al. (1979) reported that $35 \%$ of maximum oxygen uptake (also called maximum aerobic capacity or $\mathrm{VO}_{2} \max$ ) can be taken as the acceptable work load (AWL) for Indian workers which is endorsed by Nag et al, 1980 and Nag and Chatterjee, 1981. The oxygen uptake corresponding to the computed maximum heart rate in the calibration chart gives the maximum aerobic capacity $\left(\mathrm{VO}_{2} \max \right)$.

Each subject's maximum heart rate was estimated by the following relationship (Bridger, 1995).

Maximum heart rate (beats $\min ^{-1}$ ) $=200-0.65 \times$ Age in years

The mean oxygen uptake in terms of maximum aerobic capacity was calculated and it was $45 \%$ and the value was above the acceptable limit of $35 \%$ of $\mathrm{VO}_{2}$ max indicating that the power paddy weeder is could not be operated continuously for 8 hours without frequent rest-pauses. 


\section{International Journal of Science and Research (IJSR) \\ ISSN (Online): 2319-7064}

Index Copernicus Value (2013): 6.14 | Impact Factor (2014): 5.611

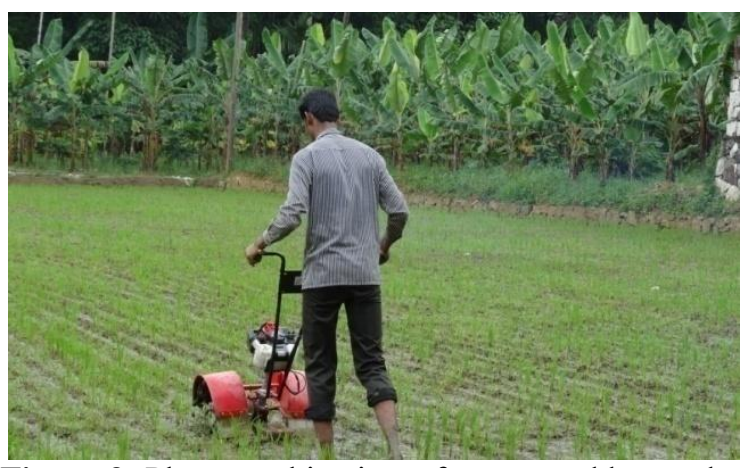

Figure 3: Photographic view of power paddy weeder working in the field

\subsection{Overall discomfort rating (ODR)}

Mean overall discomfort rating on a 10 point visual analogue discomfort scale ( 0 - no discomfort, 10- extreme discomfort ) was 3.0 and scaled as "Light discomfort" during weeding.

\subsection{Body part discomfort score (BPDS)}

The majority of discomfort was experienced in the left shoulder, right shoulder, left wrist, right wrist, left thigh and right thigh region for all the subjects during weeding and the body part discomfort score of subjects during weeding with power paddy weeder was 24.12 .

\subsection{Limit of continuous performance (LCP)}

The work pulse $(\Delta \mathrm{HR})$ was 37 beats $\min ^{-1}$ and it was within the limit of continuous performance of 40 beats $\mathrm{min}^{-1}$.

\subsection{Work rest cycle}

For every strenuous work in any field requires adequate rest to have an optimum work out put. Better performance results can be expected from both the operator and the worker only when proper attention is given for the work rest schedule for different operations.

The actual rest time taken for each subject was found from the heart rate response curves of respective operations. The rest time was measured from the cease of the operation till the heart rate of the subject reaches resting level. The rest time taken was averaged to arrive at the mean value for each selected implement.

The rest pause to the subject was calculated using the following formula as given by Pheasant (1991):

$$
R=\frac{T(E-A)}{E-B}
$$

Where.

$\mathrm{R}=$ Resting time ( $\min )$

$\mathrm{T}=$ Total working time/day $(\mathrm{min})$

$\mathrm{E}=$ Energy expenditure during working task ( $\mathrm{kcal} / \mathrm{min})$

$\mathrm{A}=$ Average level of energy expenditure considered acceptable ( $\mathrm{kcal} / \mathrm{min})$

$\mathrm{B}=$ Energy expenditure during rest $(\mathrm{kcal} / \mathrm{min})$
Average level of energy expenditure considered acceptable was $4 \mathrm{kcal} \mathrm{min}^{-1}$ (Murrel ,1965).

Rest pause was calculated using the above formula as all the subjects operated continuously for the $30 \mathrm{~min}$ period and it was found that $7 \mathrm{~min}$ rest could be provided to operator who was engaged in operating the equipment. The rest period calculated was also in agreement to the recovery heart rate of operator. If two operators are engaged with a machine in shift, it could be operated for day-long work.

\section{Conclusions}

An ergonomic evaluation of power paddy weeder is carried out at Farming Systems Research Station, Sadanandapuram, Kottarakkara, Kerala for weeding paddy in wet land cultivation. The physiological cost was found out and the mean working heart rate of operator was 108 beats $\min ^{-1}$. The operation was graded as " moderately heavy". The work pulse of the power paddy weeder is within the limit of continuous performance of 40 beats $\mathrm{min}^{-1}$. The oxygen uptake in terms of $\mathrm{VO}_{2}$ max was above the acceptable limit of $35 \%$ of $\mathrm{VO}_{2}$ max indicating that the power paddy weeder was could not be operated continuously for 8 hours without frequent rest-pauses. It is suggested that two operators may be engaged in shift for a day long work with power paddy weeder. The weeding index was found to be $85 \%$. Area covered by the power paddy weeder was 25 cent/hour while for cono weeder it was 15 cent/ hour for mechanical transplanted paddy (row to row spacing is $23.8 \mathrm{~cm}$ while using self propelled rice transplanter). Mean overall discomfort rating on a 10 point visual analogue discomfort scale ( 0 - no discomfort, 10- extreme discomfort ) was 3.0 and scaled as "Light discomfort".

\section{References}

[1] Anonymous, 1985. RNAM test codes and procedure for farm machinery, Technical series No. 12, Economic and Social Commission for Asia and the Pacific, Regional Network for Agricultural Mechanization, Bangkok, Thailand.

[2] Bridger, R. S.1995. Introduction to Ergonomics. $3^{\text {rd }}$ Edn., Mc Graw-HIll, Inc, New york.

[3] Corlett, E.N. and R.P.Bishop.1976. A technique for assessing postural discomfort, Ergonomics, 19,175-182.

[4] Gite, L. P. and B. G. Yadav. 1990. Optimum handle height for a push-pull type manually operated dryland weeder, Ergonomics, 33(12): 1487-1494.

[5] Gite, L.P and G Singh.1997. Ergonomics in agricultural and allied activities in India, Technical Bulletin No. CIAE/97/70.

[6] Grandjean, E.1982. Fitting the task to the man- An ergonomic approach, Taylor\& Francis Ltd., London

[7] Kroemer, K. H. E., H.B.Kroemer and K. E. E. Kroemer.2000. Ergonomics-How to design for ease and efficiency, Prentice-Hall Inc., Upper saddle River, New Jersey

[8] Murrell, K. F. H. 1965. Human performance in industry. Reinhold Publishing Corporation, New York.

[9] Nag, P.K., Sebastian, N.C. and M.G. Malvankar.1980. Occupational workload of Indian agricultural workers, Ergonomics, 23, 91-102. 


\section{International Journal of Science and Research (IJSR) \\ ISSN (Online): 2319-7064}

Index Copernicus Value (2013): 6.14 | Impact Factor (2014): 5.611

[10] Nag, P. K. and P. Datt. 1979. Effectiveness of some simple agricultural weeders with reference to physiological responses, Journal of Human Ergology, 8: 13-21.

[11]Nag, P. K. and S.K. Chatterjee.1981. Physiological reactions of female workers in Indian agricultural work, Human Factors, 23, 607-14.

[12] Phesant, S.1991. Ergonomics, Work and Health. London:The Macmillan Press Ltd.

[13] Saha, P. N., Datta, S. R., Banergee, P. K. and G. G. Narayanee. 1979. An acceptable work-load for Indian workers, Ergonomics, 22(9), 1059-1071.

[14] Sam, B.2014. Ergonomic evaluation of paddy harvester and thresher with farm women. International Journal of Science and Research, 3(11): 1644-1648.

[15] Sen, R.N. 1969. Tentative classification of strains in different types of jobs according to the physiological responses of young Indian workers in comfortable climates, ICMR report, Indian Council of Medical Research, New Delhi. 